\title{
Prevalence of symptoms of dyspepsia in the community
}

\author{
Roger Jones, Susan Lydeard
}

\begin{abstract}
To study the prevalence of dyspepsia in the community a postal questionnaire was sent to 2697 patients who were selected at random from the lists of patients registered in two health centres in Hampshire. A total of 2066 returned questionnaires were suitable for analysis (response rate $\mathbf{7 7 \%}$ ). It was found that the six month prevalence of dyspepsia was $38 \%$. There was considerable overlap between symptoms of heartburn and upper abdominal pain, with over half of patients with dyspepsia experiencing both. One in four of these patients had consulted their general practitioner during that time. The proportion of patients with dyspepsia who consulted their general practitioner varied widely among the eight doctors who participated in the study, from $17 \%$ to $45 \%$. Frequency of symptoms tended to fall with age, particularly in men, while the proportion of patients with dyspepsia who sought medical advice increased with age. Almost one in five of the 2066 patients had been investigated with radiology or endoscopy at some time, and $143(7 \%)$ of them claimed to have had a diagnosis of peptic ulcer.
\end{abstract}

\section{Introduction}

Dyspepsia is a common reason for patients to consult general practitioners and accounts for $3-4 \%$ of consultations. Dyspepsia is also a common symptom in the community, although little information about the epidemiology of dyspepsia has been published since the studies of Doll et $a l^{1}$ and Weir and Backett, ${ }^{2}$ who found a prevalence of appreciable dyspepsia of 25 $30 \%$. There is evidence, however, that the epidemiology and possibly the natural history of peptic ulcer disease has changed substantially in recent decades. ${ }^{3-8}$ For example, older women who take nonsteroidal antiinflammatory drugs are now at special risk. ${ }^{9}$ Despite the introduction of potent agents for healing ulcers peptic ulceration remains a serious medical problem: 30000 people are admitted to hospital in the United Kingdom each year with upper gastrointestinal haemorrhage and 3000 die. ${ }^{10}$

To be able to make the right decisions for managing such common disorders in general practice we need to know their clinical epidemiology. We now have access to expensive tools for investigating and treating dyspepsia and to use them wisely we need up to date information about the importance of common symptoms.

Department of Primary Medical Care, University of Southampton

Roger Jones, MRCGP, senior lecturer

Susan Lydeard, BSC, research assistant

Correspondence to: Dr Roger Jones, Aldermoor Health Centre, Aldermoor Close, Southampton SOl 6ST.

BrMed f 1989;298:30-2.
This paper reports on a study of the pattern, prevalence, and distribution of dyspepsia in the community with particular reference to the use of self care and primary care, and our findings may help general practitioners to formulate appropriate management responses.

\section{Patients and methods}

The patients we studied were drawn from the lists of eight general practitioners from health centre practices in the city of Southampton, Hampshire, and in the market town of Andover, Hampshire. Patients were divided by sex and stratified into 10 year age bands from age 20 and over. A one in five sample was obtained within each age band, using tables of random numbers.

On a postal questionnaire, previously validated and shown to be reliable, information was sought about occupation, employment, and whether the respondent had ever had "indigestion" for more than a few days, whether the symptoms were in the upper abdomen or whether they had the characteristics of heartburn, whether they had been present in the preceding six months, and whether the respondent had consulted a doctor about them. Information was also obtained about whether respondents had had a diagnosis of peptic ulcer and had ever had a barium meal or endoscopy. One reminder was sent. The data were analysed using a standard SAS package.

\section{Results}

A total of 2697 questionnaires were sent out, and $2066(77 \%)$ of these could be evaluated. Response rates varied considerably among participating doctors (table I) and among patients in different age groups (table II), with response rates within the 10 year age bands ranging fron $65 \%$ to $88 \%$.

Non-responders - A review of the notes of a one in four sample of non-responders showed that they were low users of medical care (mean yearly consultation rate $1 \cdot 5$ ). No patients with peptic ulcer disease were identified in this group $(n=98)$. Only four had mentioned dyspeptic symptoms in consultations during the preceding six months.

Demographic characteristics-Men and women were represented almost equally in the study (939 (45\%) men and 1127 (55\%) women). Table III gives the social

TABLE I - Response rates to postal questionnaire of patients of eight participating general practitioners

\begin{tabular}{lrrrrrrrrrr}
\hline & \multicolumn{10}{c}{ Doctor } \\
\cline { 2 - 7 } & A & B & C & D & E & F & G & H & Total \\
\hline No of questionnaires sent & 333 & 359 & 322 & 400 & 401 & 276 & 308 & 296 & 2697 \\
No(\%) responding & $236(71)$ & $273(76)$ & $200(62)$ & $327(82)$ & $317(79)$ & $215(78)$ & $246(80)$ & $252(85)$ & 2066 \\
No (\%) gone away or deceased & $47(14)$ & $29(8)$ & $55(17)$ & $24(6)$ & $36(9)$ & $19(7)$ & $16(5)$ & $9(3)$ & 236 \\
No(\%) of non-responders & $50(15)$ & $57(16)$ & $67(21)$ & $49(12)$ & $48(12)$ & $42(15)$ & $46(15)$ & $35(12)$ & 395 \\
\hline
\end{tabular}




\begin{tabular}{lcccccccc}
\hline & \multicolumn{1}{c}{ Age (years) } \\
\cline { 2 - 6 } & $20-29$ & $30-39$ & $40-49$ & $50-59$ & $60-69$ & $70-79$ & +80 & Total \\
\hline No of questionnaires sent & 564 & 565 & 448 & 364 & 369 & 262 & 125 & 2697 \\
No $(\%)$ responding & $368(65)$ & $413(73)$ & $347(77)$ & $293(80)$ & $325(88)$ & $220(84)$ & $100(80)$ & $2066(77 \%)$ \\
No $(\%)$ gone away or deceased & $67(12)$ & $56(10)$ & $35(8)$ & $32(9)$ & $15(4)$ & $16(6)$ & $15(12)$ & $236(9 \%)$ \\
No $(\%)$ of non-responders & $129(23)$ & $96(17)$ & $66(15)$ & $39(11)$ & $29(8)$ & $26(10)$ & $10(8)$ & $395(15 \%)$ \\
\hline
\end{tabular}

TABLE III-Social class distribution of 2066 respondents in Andover

\begin{tabular}{lcc}
\hline & \multicolumn{2}{c}{ No $(\%)$ of respondents } \\
\cline { 2 - 3 } Social class & Andover $(\mathbf{n}=1030)$ & Southampton $(\mathbf{n}=1036)$ \\
\hline I & $62(6)$ & $21(2)$ \\
II & $381(37)$ & $238(23)$ \\
III non-manual & $165(16)$ & $176(17)$ \\
III manual & $330(32)$ & $415(40)$ \\
IV & $82(8)$ & $124(12)$ \\
V & $10(1)$ & $62(6)$ \\
\hline
\end{tabular}
(urban) and Andover (semirural). Fewer respondents in Southampton were in employment than in Andover $(549(53 \%) v 680(66 \%))$, owing partly to higher unemployment in Southampton $(4.9 \% v 2.5 \%)$ but mainly to a large proportion of retired people living there $(33.5 \% v 20 \cdot 3 \%)$. When these data were compared with enumeration district figures from the Office of Population Censuses and Surveys they showed that the samples obtained in Southampton and Andover were representative of the populations from which they were drawn.

Symptoms of dyspepsia-Figure 1 shows that over one third of the respondents had never had dyspepsia and a quarter had suffered in the past but not in the previous

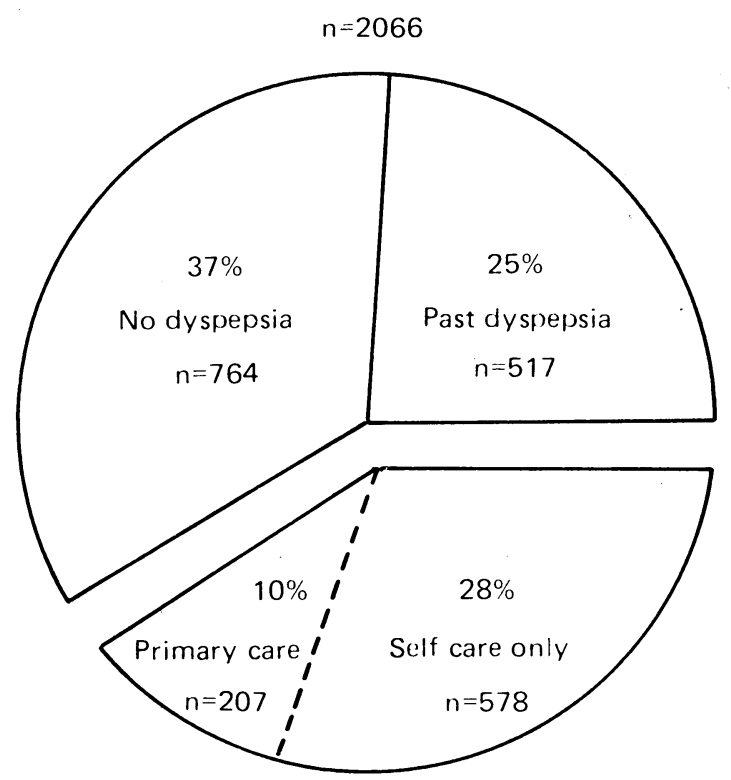

$38 \%$ Dyspepsia in past 6 months $(n=785)$

FIG 1-Frequency of dyspeptic symptoms in patients and use of self care and primary care and Southampton

class distribution of the respondents in Southampton

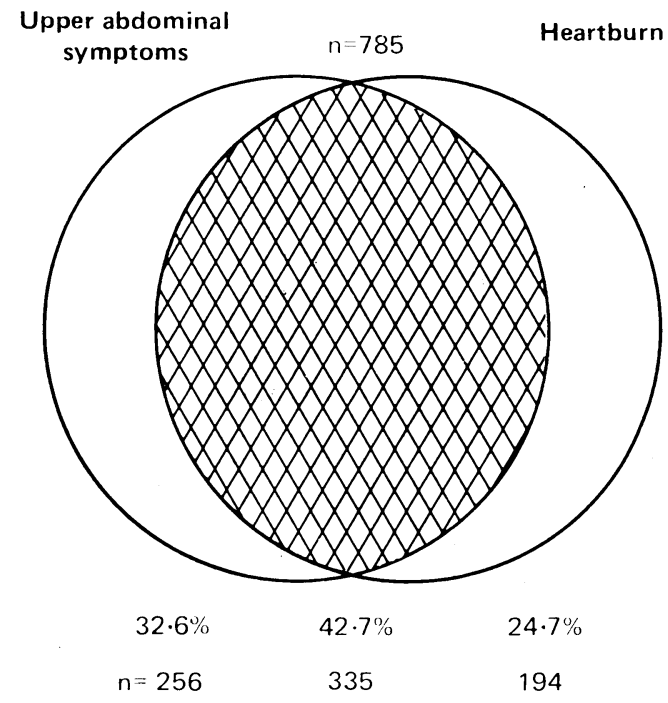

FIG 2-Distribution of upper abdominal symptoms and heartburn in patients with dyspepsia in previous six months

six months. The six month prevalence of dyspepsia was $38 \%$, and only one in four of these patients with dyspepsia had consulted their general practitioner. In each health centre almost identical proportions of respondents had experienced both upper abdominal pain or discomfort $(543(52.8 \%)$ in Andover, 535 $(51.6 \%)$ in Southampton) and heartburn $(474(46 \%)$, $471(45 \cdot 5 \%))$. Figure 2 shows, however, that almost half of those with dyspepsia had both of these symptoms. Although similar proportions of respondents had had the symptoms in the preceding six months (392 (38\%) in Andover, 414 (40\%) in Southampton), many more patients in Southampton had consulted general practitioners about them $(366(35.3 \%) v 209$ $(20 \cdot 4 \%))$. There were considerable differences in consultation rates for dyspepsia among the eight doctors (table IV). Table $\mathrm{V}$ gives the prevalence of symptoms experienced in the previous six months by patients by age and sex. There is a progressive fall in the frequency of symptoms with age, especially in men, but the proportion of patients who sought medical advice gradually increases with age.

Peptic ulceration-Over twice as many patients in Southampton as in Andover said that a peptic ulcer had been diagnosed $(104(10 \cdot 0 \%) v 47(4 \cdot 6 \%))$, and twice as many of those were men, this relation holding across all age groups.

Investigations - Similar proportions of patients (175 $(17 \%)$ in Andover, $207(20 \%)$ in Southampton) claimed to have had barium meal examinations, although the preponderance of men over women was less, and 64 $(6 \cdot 2 \%)$ patients in Andover and $75(7 \cdot 2 \%)$ in Southamp-

TABLE IV-Variation in consultation rates of patients for dyspepsia among general practitioners

\begin{tabular}{lcccccccccc}
\hline & \multicolumn{10}{c}{ Doctor } \\
\cline { 2 - 8 } & A & B & C & D & E & F & G & H & Total \\
\hline $\begin{array}{l}\text { No(\%) of respondents } \\
\begin{array}{l}\text { Six month prevalence for dyspepsia } \\
(\%)\end{array}\end{array}$ & $236(71)$ & $273(76)$ & $200(62)$ & $327(82)$ & $317(79)$ & $215(78)$ & $246(80)$ & $252(85)$ & 2066 \\
$\begin{array}{l}\text { No(\%) who consulted general } \\
\text { practitioner }\end{array}$ & $98(42)$ & $117(43)$ & $76(38)$ & $125(38)$ & $117(37)$ & $86(40)$ & $86(35)$ & $101(40)$ & 806 \\
\hline
\end{tabular}




\begin{tabular}{|c|c|c|c|c|c|c|c|c|}
\hline & \multicolumn{7}{|c|}{ Age (years) } & \multirow[b]{2}{*}{ Total } \\
\hline & $20-29$ & $30-39$ & $40-49$ & $50-59$ & $60-69$ & $70-79$ & +80 & \\
\hline \multicolumn{9}{|c|}{$\mathrm{No}(\%)$ of respondents } \\
\hline Women & $195(53)$ & $223(54)$ & $180(52)$ & $147(50)$ & $176(54)$ & $132(60)$ & $74(74)$ & $1127(55 \%)$ \\
\hline Men & $173(47)$ & $190(46)$ & $167(48)$ & $146(50)$ & $149(46)$ & $88(40)$ & $26(26)$ & $939(45 \%)$ \\
\hline \multicolumn{9}{|c|}{ Six month prevalence of dyspepsia } \\
\hline Women & $77(39)$ & $90(40)$ & $69(38)$ & $55(37)$ & $67(38)$ & $49(37)$ & $18(24)$ & $425(38 \%)$ \\
\hline Men & $76(44)$ & $80(42)$ & $62(37)$ & $50(35)$ & $49(33)$ & $28(31)$ & $4(15)$ & $349(37 \%)$ \\
\hline \multicolumn{9}{|c|}{ No who consulted general practitioner } \\
\hline Women & $13(7)$ & $20(9)$ & $16(9)$ & $19(13)$ & $29(16)$ & $26(20)$ & $12(16)$ & $135(12 \%)$ \\
\hline Men & $13(8)$ & $14(7)$ & $13(8)$ & $15(10)$ & $21(14)$ & $14(16)$ & $3(12)$ & $93(10 \%)$ \\
\hline
\end{tabular}

ton said that they had had an upper gastrointestinal endoscopy. Of the patients with dyspepsia in the previous six months who had not consulted their general practitioner $(n=578)$, a tenth had either been investigated for or had had a diagnosis of peptic ulcer at some time in the past.

Validity and repeatability-The questionnaire was found to be valid by sample interview and review of patients' notes $(n=150)$ and repeatable by sending a second questionnaire $(n=100)$.

\section{Discussion}

The results of this study show that the prevalence of symptoms of dyspepsia (38\%) has changed little since the surveys carried out by Doll et al (30\%) in $1951^{1}$ and by Weir and Backett (25\%) in 1968, ${ }^{2}$ although the observation periods in all three studies were different. Weir and Backett expressed the number of patients with peptic ulcers as a rate of all patients with dyspepsia ascertained-305/1000 compared with Doll's rate of $178 / 1000$ and ours of roughly $260 / 1000$.

Self care is obviously important and the extent of its use seems to be related to age, with less than a fifth of patients aged between 20 and 40 consulting their general practitioners, and most elderly patients seeking medical advice. Perhaps symptoms are more severe in older patients, although this seems unlikely, or perhaps older patients perceive these symptoms as being more serious. This trend is at least reassuring because the risk not only of gastrointestinal malignancy but of peptic ulceration is in part a function of increasing age.

The wide range of consultation rates among the general practitioners suggests that styles of work and, subsequently patients' expectations are also likely to influence behaviour. Although we have no information on the use of investigations by individual general practitioners in this study, the finding that only one in 10 of the non-consulting patients had previously been investigated suggests that recent dyspepsia, as defined here, refers largely to undiagnosed symptoms rather than proven peptic ulcer disease.

Making a clinical diagnosis of dyspepsia is often not straightforward, and endoscopic diagnoses are often at odds with clinical impressions. ${ }^{11}$ An international working party on dyspepsia recently classified symptoms into several categories and asserted, for example, that gastro-oesophageal reflux could be diagnosed on the basis of several clinical features. ${ }^{12}$ Our results, however, suggest that there is considerable overlap between those patients who have upper abdominal pain, discomfort, or fullness and those with symptoms more typical of reflux, including retrosternal pain and heartburn. Most of the patients with heartburn also had upper abdominal pain and vice versa. This is one reason why early clinical diagnosis may have to give way to endoscopic or radiological investigation.

The extent of investigations that patients reported in the study is surprising, with almost one fifth of the sample having had a barium meal and $138(7 \%)$ an endoscopy. The similar age distribution of patients for both investigations suggest that barium meals are still used preferentially over endoscopy; this may represent not only differences in the availability of the investigations but also a persisting view of the barium meal as the first examination in dyspepsia. The superior sensitivity and specificity of endoscopy ${ }^{13}$ suggest that this is inappropriate.

The findings confirm that symptoms of dyspepsia are common in the community and suggest that there has been no substantial change in frequency since the studies of Doll and colleagues in 1951 and Weir and Backett in 1968. The prevalence of the symptoms bears an inverse relation to the age of the patients, particularly in men, and the overlap between upper abdominal and retrosternal symptoms suggest that it is difficult to divide symptoms of dyspepsia neatly into those of oesophageal and gastroduodenal origin. The results of the study show that self care is important in managing these symptoms, with a minority of patients consulting their general practitioners about symptoms, and this consultation rate increases with age. Nevertheless, many patients were investigated for dyspepsia and about one in 10 of respondents in this study thought that they had a diagnosis of peptic ulcer at some time.

The patients we studied form the basis of a continuing study on the natural history of dyspepsia which will consider other questions about the evolution of symptoms and peptic ulcer disease over time and their management by patients and their doctors.

We thank our colleagues in Charlton Road, Andover, and Shirley Health Centre, Southampton, for their cooperation; Professors John Bain and Michael Langman for helpful comments; Nick Pready of Smith Kline and French Research for the data analysis; and SKF for supporting the study.

1 Doll R, Avery Jones F, Buckatzsch MM. Occupational factors in the aetiology of gastric and duodenal ulcers, with an estimate of their incidence in the general population. London: HMSO, 1951. (MRC Special Report Series, No 276.)

2 Weir RD, Backett EM. Studies of the epidemiology of peptic ulcer in a rura community: prevalence and natural history of dyspepsia and peptic ulcer. Gut 1968;9:75-83.

3 Langman MJS. What is happening to peptic ulcer? BrMed f 1982;284:1063-4.

4 Coggan D, Lambert P, Langman MJS. 20 years of hospital admissions for peptic ulcer in England and Wales. Lancet 1981;i:1302-4.

5 Scottish Health Service, Common Services Agency. Scrips review 2. Edinburgh: SHS, 1979.

6 Kurata JH, Honda GD, Frankl H. Hospitalization and mortality rates for peptic ulcers: a comparison of a large health maintenance organization and peptic ulcers: a comparison of a large health mainten

7 Christensen A, Bousfield R, Christiansen J. Incidence of perforated and bleeding peptic ulcers before and after the introduced $\mathrm{H} 2$-receptor antagonists. Ann Surg 1988;207:4-6.

8 Kurata JH, Haile BM, Elashoff D. Sex differences in peptic ulcer disease. Gastroenterology 1985;88:98-100.

Walt RP, Katschinski B, Logan R, et al. Rising frequency of ulcer perforatio in elderly people in the United Kingdom. Lancet 1986;i:489-92.

10 Langman MJS. Upper gastrointestinal bleeding: the trials of trials. Gut 1985;26:217-20.

11 Fiosne U, Kleveland PM, Waldum J, et al. The clinical benefit of routine upper gastrointestinal endoscopy. Scan f Gastroenterol 1986;21:433-40.

12 Working Party. Management of dyspepsia. Lancet 1988; i:576-8.

13 Colin Jones DG. When should endoscopy (or radiology) be used in dyspepsia and peptic ulcer disease? Alimentary Pharmacology and Theapeutics 1987;1: 458s-555s.

(Accepted 15 November 1988) 